\title{
Chitinibacter tainanensis gen. nov., sp. nov., a chitin-degrading aerobe from soil in Taiwan
}

\author{
Lih-Ling Chern, ${ }^{1}$ Erko Stackebrandt, ${ }^{2}$ Shu-Fen Lee, ${ }^{1}$ Fwu-Ling Lee, ${ }^{1}$ \\ Jeen-Kuan $\mathrm{Chen}^{3}$ and Huei-Mei Fu ${ }^{1}$
}

Correspondence

Fwu-Ling Lee

fll@firdi.org.tw

\author{
${ }^{1}$ Bioresource Collection and Research Centre, Food Industry Research and Development \\ Institute, PO Box 246, Hsinchu 300, Taiwan \\ ${ }^{2} \mathrm{DSMZ}$ - Deutsche Sammlung von Mikroorganismen und Zelkuturen, Mascheroder Weg 1b, \\ D-38124 Braunschweig, Germany \\ ${ }^{3}$ Department of Environment and Biotechnology, Refining and Manufacturing Research Centre, \\ Chinese Petroleum Corporation, Chia-Yi, Taiwan
}

\begin{abstract}
Five strains with strong chitinolytic activity were isolated from a soil sample collected from southern Taiwan. The strains shared more than $92 \%$ DNA-DNA similarity, indicating membership of the same genospecies. This close relationship was supported by high similarities in fatty acid composition and biochemical characteristics. A 16S rRNA gene sequence analysis indicated that the isolates were members of the class 'Betaproteobacteria', in which they formed an individual subline of descent that was distantly related ( $<94 \%$ similarity) to lineages defined by Formivibrio citricus DSM $6150^{\top}$ and lodobacter fluviatilis DSM $3764^{\top}$. On the basis of the phylogenetic and phenotypic distinctness of these novel chitin-degrading organisms, a new genus, Chitinibacter, is proposed, with Chitinibacter tainanensis (type strain, $S 1^{\top}=$ BCRC $17254^{\top}=$ DSM $15459^{\top}$ ) as the type species.
\end{abstract}

Next to cellulose, chitin is the second most-abundant polysaccharide on Earth, as it is a major component of most fungal cell walls, insect exoskeletons and the shells of crustaceans (Flach et al., 1992). Derivatives of chitin, including polysaccharides, oligosaccharides and monosaccharides, have been shown to play a role in the organogenesis of plants and the embryogenesis of invertebrates (Bakkers et al., 1997). Recently, chitin oligosaccharides have been demonstrated to enhance functions of the immunological system in host animals, possibly functioning as tumoricidal agents (Suzuki et al., 1986). To prepare functional chitin derivatives, micro-organisms were isolated from soils and screened for chitinase activities. This report deals with the detailed characterization of five strains of bacteria with strong chitinolytic activity and with the proposal of Chitinibacter tainanensis gen. nov., sp. nov.

Chitinolytic bacteria were isolated from various soil samples collected from Tainan Prefecture in the southern part of Taiwan, using agar medium containing $0.2 \%$ colloidal chitin (Hsu \& Lockwood, 1975) as a selective medium. The

The GenBank/EMBL/DDBJ accession number for the 16S rRNA gene sequence of Chitinibacter tainanensis $\mathrm{S}^{\top}{ }^{\top}$ is AY264287.

The phenotypic characteristics (Table A) and cellular fatty acid compositions (Table B) of the novel chitin-degrading strains, and DNA-DNA hybridization results (Table $\mathrm{C}$ ), are available as supplementary data in IJSEM Online. reduced sugars formed in the medium, indicating the degradation of chitin, were detected according to a modified procedure of Imoto \& Yagishita (1971). Colonies with surrounding clear zones were selected and incubated at $30^{\circ} \mathrm{C}$ in Luria-Bertani (LB) medium (Life Science).

Micro-organisms used for comparison with the isolated chitin-degrading strains were Alcaligenes latus ATCC $29712^{\mathrm{T}}$ [obtained from the American Type Culture Collection (ATCC), Manassas, VA, USA], Iodobacter fluviatilis DSM $3764^{\mathrm{T}}$ and Formivibrio citricus DSM $6150^{\mathrm{T}}$ [both obtained from the Deutsche Sammlung von Mikroorganismen und Zelkulturen (DSMZ), Braunschweig, Germany]. Growth media for I. fluviatilis and A. latus were nutrient agar (Difco) and brain-heart infusion medium (Difco), while F. citricus was cultivated on Formivibrio medium (medium DSM 505; DSMZ, 2001). Cultivation was at $30^{\circ} \mathrm{C}$. Ten strains of chitin-degrading micro-organisms were isolated from soil samples collected in the southern part of Taiwan. Strains isolated from Tainan grew at $30^{\circ} \mathrm{C}$ aerobically with shaking, and showed the strongest chitin-degrading potential, as indicated by determination of the reducing power in the medium. Strain $S 1^{\mathrm{T}}$, which was deposited at the Bioresource Collection and Research Centre, Food Industry Research and Development Institute, Taiwan as C. tainanensis (as BCRC $17254^{\mathrm{T}}$ ) and at the DSMZ (as DSM $15459^{\mathrm{T}}$ ), and strains S5, S6, S9 and S12 were selected for further studies. 
All tests on the novel bacteria were performed using LB medium at $30{ }^{\circ} \mathrm{C}$ unless stated otherwise. The cell morphology of the strains was observed using a Zeiss light microscope. To visualize flagella, a drop of bacterial suspension was gently transferred to a copper grid (square 100-mesh) which was cleaned with acetone, coated with colloidin, dried in a desiccator overnight and then stabilized with carbon in a high-vacuum coating unit (HUS-5GB; Hitachi). Excess water was removed by absorption with filter paper from the side of the grid. Bacteria retained on the grid were negatively stained with $1 \%$ phosphotungstic acid $(\mathrm{pH} 7)$ for $60 \mathrm{~s}$. After the stain solution had been removed from the grid with filter paper, the images were viewed and photographed with a Hitachi H-600 transmission electron microscope. A Gram stain was performed using the Gramcolour set (Merck). Growth at various temperatures, ranging from 5 to $50^{\circ} \mathrm{C}$, using $5{ }^{\circ} \mathrm{C}$ increments, was determined on LB medium. The diameters of colonies were measured after incubation at $30{ }^{\circ} \mathrm{C}$ for 3 days. The effect of $\mathrm{pH}$ on growth was tested with $0.5 \times \mathrm{LB}$ medium buffered with $0 \cdot 2 \mathrm{M}$ citric acid and $\mathrm{Na}_{2} \mathrm{HPO}_{4}$ and adjusted to $\mathrm{pH}$ values 3,4 and 5-10 (using increments of $0 \cdot 5$ ) with $\mathrm{NaOH}$ or $\mathrm{HCl}$. Aliquots $(5 \mathrm{ml})$ of the $\mathrm{pH}$-buffered medium in $13 \times 100 \mathrm{~mm}$ screw-capped test tubes were inoculated with $0.25 \mathrm{ml}$ bacterial suspension (concentration equal to McFarland 1) prepared from a 2-day-old culture. Four replicates were used for each $\mathrm{pH}$ test. After incubation under shaking for 7 days, growth was indicated by a change in optical density at $400 \mathrm{~nm}$, measured using a spectrophotometer (Walden Precision Apparatus). The $\mathrm{pH}$ was stable during the incubation. The oxygen requirement was tested by using growth distribution following a shake-tube inoculation method (Cappuccino \& Sherman, 1987). The presence of cytochrome oxidase was tested using oxidase reagent droppers (Difco); catalase activity was determined using $\mathrm{H}_{2} \mathrm{O}_{2}$ solution as described by Koneman et al. (1979). The abilities of the strains to utilize various substrates as sole carbon sources were evaluated using the API 20NE panel (bioMérieux) and Vitek NFC cards (bioMérieux) according to the manufacturer's instructions.

Hydrolysis of chitin by the isolated strains was tested using agar medium supplemented with colloidal chitin as described above. Cytophaga sp. DSM 3657 and Serratia marcescens DSM $30121^{\mathrm{T}}$ were used as chitinase-positive control strains. I. fluviatilis DSM $3764^{\mathrm{T}}$ and F. citricus DSM $6150^{\mathrm{T}}$ were also tested, as they were phylogenetic neighbours of the novel isolates. The preparation of colloidal chitin was according to the description of Monreal \& Reese (1969). The agar medium contained the following $\left(\mathrm{l}^{-1}\right): 0.3 \mathrm{~g}$ $\mathrm{MgSO}_{4} .7 \mathrm{H}_{2} \mathrm{O}, 1.36 \mathrm{~g} \mathrm{KH}_{2} \mathrm{PO}_{4}, 1.0 \mathrm{~g}\left(\mathrm{NH}_{4}\right)_{2} \mathrm{SO}_{4}, 1.0 \mathrm{~g}$ $\mathrm{NaCl}, 4 \cdot 0 \mathrm{~g}$ colloidal chitin, 1.0 g yeast extract, $12 \cdot 0 \mathrm{~g}$ agar, $5.0 \mathrm{ml}$ trace elements (DSMZ medium 27; DSMZ, 2001) and vitamin solution (DSMZ medium 428; DSMZ, 2001). For growth of strain DSM $6150^{\mathrm{T}}$, DSMZ medium 505 was used in which malate was replaced by $1.5 \mathrm{~g}$ colloidal chitin. Tests for chitinase activity were done under aerobic conditions, except in the case of F. citricus DSM $6150^{\mathrm{T}}$, which was tested under an $\mathrm{N}_{2}$ atmosphere.

All isolates were strictly aerobic, oxidase-positive and catalase-positive. All strains showed almost identical reactions in the API and Vitek substrate-utilization panels. Results are included in the species description, and the data are available in IJSEM Online (Table A). All of the novel strains grew on LB medium and on trypticase-soy agar plus blood at temperatures ranging from 10 to $40^{\circ} \mathrm{C}$, with an optimum temperature between 30 and $37^{\circ} \mathrm{C}$. No growth was observed at 5 or $45^{\circ} \mathrm{C}$ after incubation for 14 days. Growth of the novel bacteria occurred at $\mathrm{pH} 5 \cdot 5$ $9 \cdot 0$, as indicated by the increase in optical density at $400 \mathrm{~nm}$. The optimum $\mathrm{pH}$ was around $\mathrm{pH} 7 \cdot 5$.

While the chitinase-positive reference strains Cytophaga sp. DSM 3657 and S. marcescens DSM $30121^{\mathrm{T}}$, as well as the novel isolate $S 1^{\mathrm{T}}$, were strongly positive, the reaction of I. fluviatilis DSM $3764^{\mathrm{T}}$ was very weak and delayed, producing a small clear zone of about $2 \mathrm{~mm}$ around the large colonies of $2.5 \mathrm{~cm}$ in diameter. F. citricus DSM $6150^{\mathrm{T}}$ did not grow at all on the chitin agar, while the control grew on the same medium in which chitin had been replaced by trisodium acetate. This strain should therefore be considered chitin-negative.

The ubiquinone system of the novel chitin-degrading bacteria was determined by using the method described by Collins \& Jones (1981). The TLC-purified quinones were analysed with a Nova-Pak $\mathrm{C}_{18}(15 \times 3.9 \mathrm{~cm})$ column (Waters). Peaks were detected at $275 \mathrm{~nm}$ after elution with methanol/2-propanol $(2: 1)$ at flow rate of $1 \mathrm{ml} \mathrm{min}^{-1}$. Q6, Q-7, Q-9 and Q-10 standards were purchased from Sigma. Q-8 was extracted from the A. latus ATCC $29712^{\mathrm{T}}$ culture. Q-8 was found to be the major quinone in strain $\mathrm{S1}^{\mathrm{T}}$ (98\% of the total quinones) and I. fluviatilis DSM $3764^{\mathrm{T}}(95 \%)$; this is quite common among members of the 'Betaproteobacteria'.

Cellular fatty acid compositions of the novel isolates and I. fluviatilis DSM $3764^{\mathrm{T}}$ and F. citricus DSM $6150^{\mathrm{T}}$ were determined using the Sherlock Microbial Identification System (MIDI). Extracts of the methylated fatty acids were prepared according to the protocol provided by the manufacturer and analysed with a 5890 gas chromatograph equipped with a flame ionization detector and an automatic injector with a G1512A controller (Hewlett Packard). Identification of the peaks was made by comparing the results with the built-in TSBA 40 database (MIDI). The major fatty acids ( $>1 \%$ of total fatty acids) of the chitindegrading strains were as follows: $16: 1 \omega 7 c / 15$ iso $2-\mathrm{OH}$ $(48 \cdot 45-51 \cdot 83 \%), 18: 1 \omega 7 c(17 \cdot 72-19 \cdot 85 \%), 16: 0(15 \cdot 36-$ $17 \cdot 57 \%), 12: 03-\mathrm{OH}(3 \cdot 87-4 \cdot 21 \%), 12: 0(2 \cdot 45-3 \cdot 09 \%)$, 10-methyl 19:0 (1.37-2.03\%) and 16:0 3-OH $(1 \cdot 24-$ $1 \cdot 44 \%)$. A complete listing of the fatty acids is available in IJSEM Online (Table B). The differences in fatty acid profiles of phylogenetically related species are listed in Table 1. 
Table 1. Differential characteristics of C. tainanensis from phylogenetically related species

\begin{tabular}{|c|c|c|c|}
\hline Characteristic & $\begin{array}{l}\text { C. tainanensis } \\
\qquad S 1^{\mathrm{T}}\end{array}$ & $\begin{array}{c}\text { F. citricus } \\
{\text { DSM } 6150^{\mathrm{T}}}^{*}\end{array}$ & $\begin{array}{c}\text { I. fluviatilis } \\
\text { NCTC } 11159^{\mathrm{T}} \dagger\end{array}$ \\
\hline Anaerobic growth & - & + & - \\
\hline Chitin hydrolysis & + & - & Weak (delayed) \\
\hline \multicolumn{4}{|l|}{ Cellular fatty acids $\ddagger$} \\
\hline $12: 03-\mathrm{OH}$ & $3 \cdot 87-4 \cdot 21 \%$ & -/Trace & $2-3 \%$ \\
\hline $14: 0$ & Trace & $2 \cdot 2 \%$ & $8 \cdot 4 \%$ \\
\hline $14: 03-\mathrm{OH}$ & - & $9 \cdot 5 \%$ & - \\
\hline 10-methyl 19:0 & $1 \cdot 37-2 \cdot 03 \%$ & - & - \\
\hline Growth at $40^{\circ} \mathrm{C}$ & + & - & - \\
\hline $\mathrm{G}+\mathrm{C}$ content $(\mathrm{mol} \%)$ & $55 \cdot 9-56 \cdot 2$ & 61 & $50-52$ \\
\hline Major quinone & Q-8 & ND & Q-8 \\
\hline
\end{tabular}

ND, Not determined.

${ }^{\star}$ Data for F. citricus were taken from Logan (1989), except for chitin hydrolysis and cellular fatty acids.

$\dagger$ Data for I. fluviatilis were taken from Tanaka et al. (1991) and Hippe et al. (1999), except for chitin hydrolysis and cellular fatty acids.

¥All five strains of $C$. tainanensis were tested.

Isolation of genomic DNA for sequence analysis was done as described by Franke et al. (1999). PCR amplification of the $16 \mathrm{~S}$ rRNA gene and the subsequent cycle sequencing reaction were carried out using the MicroSeq $16 \mathrm{~S}$ rRNA gene kit (Applied Biosystems). The products were analysed with a PRISM 310 genetic analyser (Applied Biosystems). Phylogenetic analyses was performed by using different treeing algorithms [distance matrix (De Soete, 1983; Felsenstein, 1993); neighbour joining and maximum parsimony (Felsenstein, 1993)].

Analysis of the 16S rRNA gene sequence of strain $\mathrm{S1}^{\mathrm{T}}$, consisting of $1514 \mathrm{nt}$, revealed its closest phylogenetic neighbours to be F. citricus DSM $6150^{\mathrm{T}}$ (Y17602) and I. fluviatilis ATCC $33051^{\mathrm{T}}(\mathrm{M} 22511)$, members of the 'Betaproteobacteria', with similarity values of $93.4 \%$ and $90.6 \%$, respectively. Partial $16 \mathrm{~S}$ rRNA gene sequence analysis (positions 13-518 according to the Escherichia coli numbering system; Brosius et al., 1978) of the other four chitin-degrading isolates revealed $100 \%$ identity with the homologous stretch of strain $\mathrm{S}^{\mathrm{T}}$. Different treeing algorithms gave consistent results by placing the chitindegrader as a new lineage between the Formivibrio and Iodobacter lineages (Fig. 1). The order of branching points within this cluster is not stable as judged from the bootstrap value of $64 \%$.

A commercial kit (Genomic-tips; Qiagen) was used for the preparation of genomic DNA for determination of the base composition of the DNA (mol\% G $+\mathrm{C}$ content) and DNA-DNA reassociation. The $\mathrm{G}+\mathrm{C}$ content was determined by using reversed-phase HPLC (Tamaoka \& Komagata, 1984) with slight modifications. The nucleotides were separated using a Cosmosil $5 \mathrm{C}_{18}$ column $(4 \cdot 0 \times 150 \mathrm{~mm})$ (Waters) in a mobile phase composed of $0 \cdot 2 \mathrm{M} \mathrm{NH}_{4} \mathrm{H}_{2} \mathrm{PO}_{4} /$ acetonitrile $(20: 1, \mathrm{v} / \mathrm{v})$ at a flow rate of
$1 \mathrm{ml} \mathrm{min}{ }^{-1}$ at room temperature. The nucleotides were detected and quantified by absorption at $270 \mathrm{~nm}$. DNA similarity values between the chitin-degrading strains, and between two of these strains and the phylogenetically nearest type strains of other species, were determined using the fluorometric hybridization method in microdilution wells (Ezaki et al., 1989). The fluorescence intensity of each well was measured with a Fluoroskan II microplate fluorometer (Labsystems) at a wavelength of $360 \mathrm{~nm}$ for excitation and at $450 \mathrm{~nm}$ for emission. The chitin-degrading

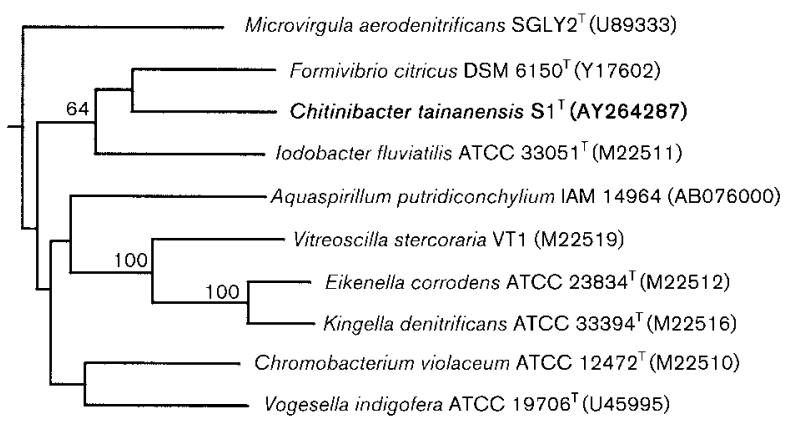

$0 \cdot 10$

Fig. 1. Phylogenetic tree, based on 16S rRNA gene sequences, showing the nearest neighbours of the novel chitindegrading bacterium in the class 'Betaproteobacteria'. The bar corresponds to a $10 \%$ difference in nucleotide sequences, as determined by measuring the lengths of the horizontal lines connecting any two organisms. The numbers shown at the branch points indicate percentage bootstrap values from 1000 datasets. Only bootstrap values greater than $60 \%$ are shown. 
strains had a DNA G $+\mathrm{C}$ content ranging from $55 \cdot 9$ to $56 \cdot 2 \mathrm{~mol} \%$. This value is significantly lower than the $61 \mathrm{~mol} \%$ determined for F. citricus DSM $6150^{\mathrm{T}}$ (Hippe et al., 1999) and higher than the $50-52 \mathrm{~mol} \%$ of $I$. fluviatilis NCTC $11159^{\mathrm{T}}$ (Logan, 1989). The DNA similarity test revealed that the five strains shared high DNA similarity values (92-100\%), indicating membership of the same genospecies. DNA similarity values between strain $S 1^{\mathrm{T}}$ or strain S12 and F. citricus DSM $6150^{\mathrm{T}}$ and I. fluviatilis DSM $3764^{\mathrm{T}}$ were below $10 \%$.

The five isolates from Taiwanese soil were identical with respect to morphology, physiology, chemotaxonomy and genomic properties, and should be considered members of the same taxon. Phylogenetically, they form a novel line of descent within the 'Betaproteobacteria', with Formivibrio and Iodobacter as the closest (albeit remote) neighbours. Strain $\mathrm{S1}^{\mathrm{T}}$ and the four similar strains (S5, S6, S9 and S12) can be clearly distinguished from the two phylogenetic neighbours which form two clearly separate genomic entities, as judged from the low sequence-similarity values. The most salient property is the degradation of chitin, a characteristic that is weak or absent in the type strains of the phylogenetic neighbours. Other characteristics separating the chitinolytic taxon from Formivibrio and Iodobacter are listed in Table 1. Although some chitinolytic bacteria have been shown to be insect pathogens (Sampson \& Gooday, 1998), the question of whether these new Taiwanese strains are pathogenic to insects remains to be investigated.

\section{Description of the genus Chitinibacter gen. nov.}

Chitinibacter (chi.ti.ni.bac'ter. N.L. n. chitinum chitin; N.L. masc. n. bacter rod; N.L. masc. n. Chitinibacter rod that degrades chitin).

Strictly aerobic, Gram-negative rods that are straight to slightly curved (Fig. 2a) with round ends, $1 \cdot 3-2 \cdot 6 \mu \mathrm{m}$ in length and $0 \cdot 5-0.9 \mu \mathrm{m}$ in width. Highly motile by means of one polar flagellum or two polar flagella (Fig. 2b, c). Oxidase- and catalase-positive. No acid from glucose. Q8 is the predominant isoprenoid quinone. Major fatty acids $(>5 \%)$ are $16: 1 \omega 7 c / 15$ iso $2-\mathrm{OH}(48 \cdot 45-51 \cdot 83 \%)$, $18: 1 \omega 7 c(17 \cdot 72-19 \cdot 85 \%)$ and $16: 0(15 \cdot 36-17 \cdot 57 \%)$. Phylogenetically, a member of the class 'Betaproteobacteria'. The $\mathrm{G}+\mathrm{C}$ content of the DNA is $56 \mathrm{~mol} \%$.

The type species is Chitinibacter tainanensis.

\section{Description of Chitinibacter tainanensis sp. nov.}

Chitinibacter tainanensis (tai.na.nen'sis. N.L. adj. tainanensis referring to Tainan, a town in Southern Taiwan, the origin of the soil sample from which the type strain was isolated).

In addition to the properties defining the genus, strains of the species form milky white, circular, entire, convex colonies on LB agar, measuring $0 \cdot 5-2 \cdot 0 \mathrm{~mm}$ in diameter. Growth occurs at temperatures from 10 to $40^{\circ} \mathrm{C}$, with the
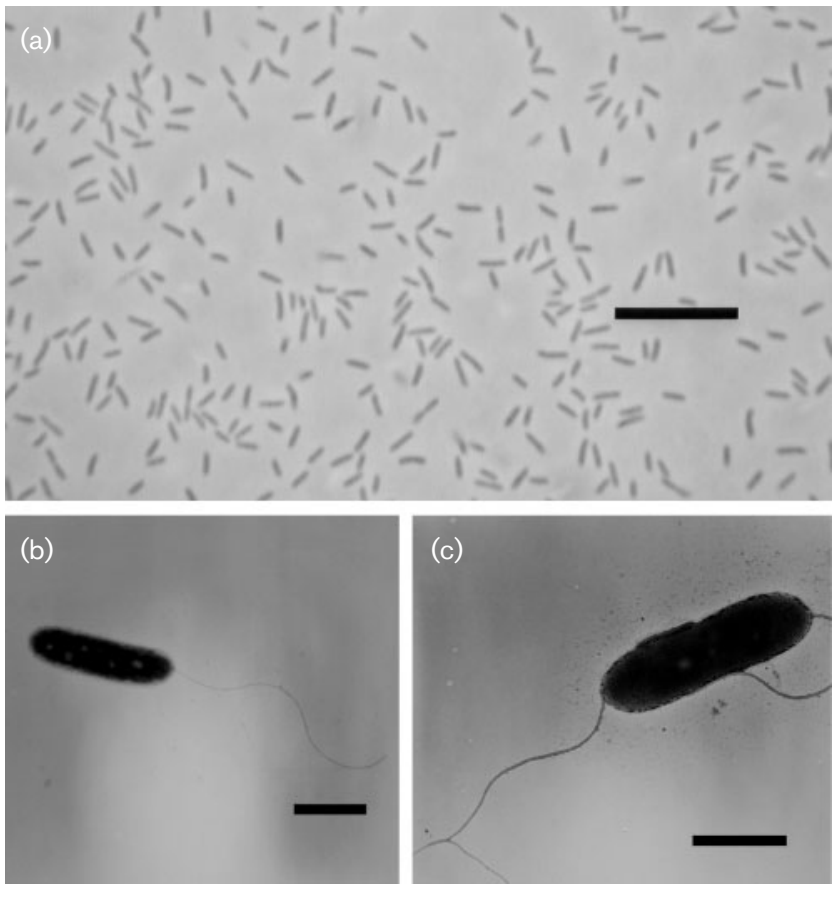

Fig. 2. Phase-contrast photomicrograph (a) and negatively stained electron micrographs $(b, c)$ of $C$. tainanensis cells, showing one polar flagellum or two polar flagella. Bars: $10 \mathrm{~mm}$ (a); $1 \mu \mathrm{m}(\mathrm{b}, \mathrm{c})$.

optimum at $30-37^{\circ} \mathrm{C}$, and at $\mathrm{pH}$ values from $5 \cdot 5$ to $9 \cdot 0$, with the optimum at $\mathrm{pH} 7 \cdot 5$. Negative for nitrate reduction, indole production, arginine dihydrolase, urease, $\beta$-glucosidase, $\beta$-galactosidase and protease. On the basis of API and Vitek tests, glucose, $\mathrm{N}$-acetylglucosamine and gluconate are utilized. The following are not utilized: arabinose and D-mannose (strain S6 gave a weak reaction for both in API tests), D-mannitol, maltose and citrate. API tests were negative for maltose, caprate, adipate, malate and phenyl acetate. Vitek tests were negative for myoinositol, D-galactose, sucrose, trehalose, D-xylose, DL-lactate, sodium acetic acid, propionic acid, adipic acid, itaconic acid, suberic acid, sebacic acid, azelaic acid, heptanoic acid, L-aspartic acid, L-alanine, L-histidine and L-proline. Isolated from Taiwan, near Tainan Prefecture (120 16 $21^{\prime \prime} \mathrm{E}$ $\left.23^{\circ} 13^{\prime} 09^{\prime \prime} \mathrm{N}\right)$.

Type strain is $\mathrm{S}^{\mathrm{T}}\left(=\mathrm{BCRC} 17254^{\mathrm{T}}=\mathrm{DSM} 15459^{\mathrm{T}}\right)$.

\section{Acknowledgements}

This research was supported partially by the Taiwanese Ministry of Economic Affairs (project no. 02M094-05). We would like to thank S.-Y. Hsieh for his help with the preparation of electron micrographs, Y.-M. Ju for his advice on nomenclature, I.-B. Chen for assistance with the Vitek tests, and Y.-C. Wu for providing anaerobic culture techniques. A. Frühling is thanked for her involvement in the chitinase tests. Special thanks go to T. Y. Liu, C. C. Liao and G. F. Yuan (Food Industry Research and Development Institute, Taiwan, Republic of China) for their encouragement. 


\section{References}

Bakkers, J., Semino, C. E., Stroband, H., Kijne, J. W., Robbins, P. W. \& Spaink, H. P. (1997). An important developmental role for oligosaccharides during early embryogenesis of cyprinid fish. Proc Natl Acad Sci U S A 94, 7982-7986.

Brosius, J., Palmer, M. L., Kennedy, P. J. \& Noller, H. F. (1978). Complete nucleotide sequence of a $16 \mathrm{~S}$ ribosomal RNA gene from Escherichia coli. Proc Natl Acad Sci U S A 75, 4801-4805.

Cappuccino, J. G. \& Sherman, N. (1987). Microbiology: a Laboratory Manual. Menlo Park, CA: Benjamin/Cummings Publishing.

DSMZ (2001). Catalogue of Strains, 7th edn. Braunschweig: Deutsche Sammlung von Mikroorganismen und Zelkuturen.

Collins, M. D. \& Jones, D. (1981). A note on the separation of natural mixtures of bacterial ubiquinones using reverse-phase partition thinlayer chromatography and high performance liquid chromatography. J Appl Bacteriol 51, 129-134.

DeSoete, G. (1983). A least squares algorithm for fitting additive trees to proximity data. Psychometrika 48, 621-626.

Ezaki, T., Hashimoto, Y. \& Yabuuchi, E. (1989). Fluorometric deoxyribonucleic acid-deoxyribonucleic acid hybridization in microdilution wells as an alternative to membrane filter hybridization in which radioisotopes are used to determine genetic relatedness among bacterial strains. Int J Syst Bacteriol 39, 224-229.

Felsenstein, J. (1993). PHYLIP (phylogeny inference package), version 3.5c. Department of Genetics, University of Washington, Seattle, USA.

Flach, J., Pilet, P. E. \& Jolles, P. (1992). What's new in chitinase research? Experientia 48, 701-716.

Franke, I. H., Fegan, M., Hayward, C., Leonard, G., Stackebrandt, E. \& Sly, L. I. (1999). Description of Gluconacetobacter sacchari sp. nov., a new species of acetic acid bacterium isolated from the leaf sheath of sugar cane and from the pink sugar-cane mealy bug. Int J Syst Bacteriol 49, 1681-1693.
Hippe, H., Hagelstein, A., Kramer, I., Swiderski, J. \& Stackebrandt, E. (1999). Phylogenetic analysis of Formivibrio citricus, Propionivibrio dicarboxylicus, Anaerobiospirillum thomasii, Succinimonas amylolytica and Succinivibrio dextrinosolvens and proposal of Succinivibrionaceae fam. nov. Int J Syst Bacteriol 49, 779-782.

Hsu, S. C. \& Lockwood, J. L. (1975). Powdered chitin agar as a selective medium for enumeration of actinomycetes in water and soil. Appl Microbiol 29, 422-426.

Imoto, T. \& Yagishita, K. (1971). A simple activity measurement of lysozyme. Agric Biol Chem 35, 1154-1156.

Koneman, E., Allen, S., Dowell, V. \& Sommers, H. (1979). Color Atlas and Textbook of Diagnostic Microbiology, pp. 216-217. Philadelphia: J. B. Lippincott.

Logan, N. A. (1989). Numerical taxonomy of violet-pigmented, Gram-negative bacteria and description of Iodobacter fluviatile gen. nov., comb. nov. Int J Syst Bacteriol 39, 450-456.

Monreal, J. \& Reese, E. T. (1969). The chitinase of Serratia marcescens. Can J Microbiol 15, 689-696.

Sampson, M. N. \& Gooday, G. W. (1998). Involvement of chitinases of Bacillus thuringiensis during pathogenesis in insects. Microbiology 144, 2189-2194.

Suzuki, K., Mikami, T., Okawa, Y., Tokoro, A., Suzuki, S. \& Suzuki, M. (1986). Antitumor effect of hexa- $N$-acetylchitohexaose and chitohexaose. Carbohydr Res 151, 403-408.

Tamaoka, J. \& Komagata, K. (1984). Determination of DNA base composition by reversed-phase high-performance liquid chromatography. FEMS Microbiol Lett 25, 125-128.

Tanaka, K., Nakamura, K. \& Mikami, E. (1991). Fermentation of S-citramalate, citrate, mesaconate, and pyruvate by a Gram-negative strictly anaerobic non-spore-former, Formivibrio citricus gen. nov., sp. nov. Arch Microbiol 155, 491-495. 